\title{
2 次核発生速度を考虑した分級層型晶析装置の設計法
}

\author{
豊 倉賢・矢後夏之助 \\ 山 添勝 己 \\ 早稲田大学理工学部 化学工学分科* \\ 青 山 吉 雄 \\ 大同化工機 $(\text { 株 })^{* *}$
}

\section{緒言}

工業装置として広く用いられている分級層型晶析装置 の設計法汇ついて，著者らは晶析特性因子 (C.F.D.) (C.F.S.R.)*** に基づく一連の設計式を提出している ${ }^{6)}$. この設計式は，装置内結晶の成長速度に基づくもので， 入口溶液過飽和度をパイロットテストのそれと同じにと ると, 工業装置内の核発生速度はパイロット装置内のそ れとほぼ等しくなるとして用いられている。この設計法 は，硫酸ナトリウム系関して報告したように1)，千倍 ぐらいまでのスケールアップが可能であると考兄られる が，さらに小さい実験室規模の装置から実装置までのス ケールアップを行らには, 核発生速度も成長速度と同様 に考慮する必要がある. 核発生, 特に装置内で支配的に 起こると考えられる 2 次核発生速度に関しては，近年多 くの研究が行われてきているが3), 奏装置の設計, 操作 法に適用できるように定量化されたものはき称めて少な い. 著者らは, 前報》にてカリ明攀系の流動層内 2 次核 発生速度について研究を行い, 2 次核発生速度をレイ, ルズ数および過飽和度の指数関数として定量化してい る. 本研究では, 2 次核発生速度がレイノルズ数拉よび 過飽和度によって定量化できるような系を対象にして， 2 次核発生速度を考慮した, 新しい分級層型晶析装置の 設計法を提出する。 また，この設計法を用いて，あらか じめ設計されている晶析装置より生産される結晶の粒径 と生産速度との関保について推算する方法を提出すると ともに, この推算結果と工業操作データとを比較, 検討 したので報告する.

\section{1. 設 計 法}

分級層型晶析装置の設計にあたって, 結晶成長部本体

* 160 新宿区西大久保 4-170

** 554 大阪市此花区高見 1-3-34

*** 分級㸴型晶析装置の設計法に関する Saeman らの研究では, 塔頂過飽和度を 0 としているが，工業装置では 0 ではなくそそ れを考應すると設計式は複雑となり, 計算も繁雑になる。しか し, 入口出口の粒径比や過飽和度比に基ついて提出された (C.F.D.), (C.F.S.R.) を用いると簡便に計算できる。
内に存在する結晶および溶液の挙動を次のようにモデル 化する.

1）装置内では結晶, 溶液ともピストン流とし, 半径 方向の濃度および粒径分布はないものとする，結晶核は 前報》で報告した 2 次核発生速度 Eq. (1)

$$
f^{\prime}=\alpha(R e)^{\beta}(\Delta C)^{r}
$$

に従って発生するものとし，いったん発生した結晶核は 減少することなく溶液とともに系内を循環しつつ成長す る.核より成長した結晶は流動層の流動特性に基づいた 装置内の所定位置に浮遊し，粒径に対して塔高方向に完 全分級されているものとする.

2）結晶の成長速度に関して，前報1,8) では拡散段階 と表面晶析段階とからなる直列機構に基づいた関係式を 使用した. その後, Mullin ${ }^{5)}$, その他年の研究において, 結晶成長速度に対する粒径の影響の有無が検討されてい るが，工業装置の設計を前提とした結晶成長速度として は，粒径の影響を総括的に表現した Branson モデルに 基づく結晶成長速度 Eq. (2) が妥当と考宎，これを使用 する.

$$
R_{g}=K_{g} l^{b} \Delta C^{n}
$$

\section{1 ・1 円筒分級層型晶析装置の設計法}

装置内微小層高 $d Z$ 中の結晶成長に基づく物質收支 は，前報と同様に Eq. (3) となり，

$$
S d Z a R_{g}=-\rho_{c} F_{0}{ }^{\prime} d v
$$

塔高 $Z$ は, Eq. (5) で定義される晶析操作特性因子, (C.F.C.) $)_{n}$ を用いて，Eq. (4) となる.

$$
\begin{gathered}
Z=\frac{3 \rho_{c} k_{v}{ }^{2} f_{0}{ }^{\prime} l_{2}{ }^{4-b}}{K_{g} \Delta C_{1}{ }^{n} k_{a}}(\text { C.F.C. })_{n} \\
(\text { C.F.C. })_{n}=\int_{1}^{y_{1}} \frac{\phi_{n} y^{3-b} d y}{\left(1-\varepsilon_{2} y^{-1 / 3}\right)\left\{1+(\phi-1)\left(y^{3}-1\right) /\left(y_{1}{ }^{3}-1\right)\right\}^{n}}
\end{gathered}
$$

また装置断面積 $S$ は前報成様, 物質収支より Eq. (6) となる.

$$
S=P_{1}\left(1-1 / y_{1}^{3}\right) \phi \mid f M \Delta C_{1}(\phi-1)
$$

ここで(C.F.C.) $)_{n}$ は $b, n, \varepsilon_{2}$ によって变わるが，前報に おける (C.F.C.), (C.F.S.R.) と同様，y, $\phi$ の関数として 


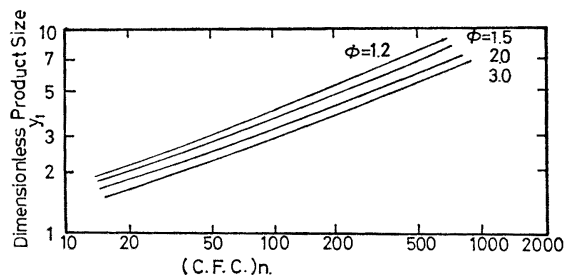

Fig. 1 Correlation between (C.F.C.) $)_{n}$, and dimensionless product size $y_{1}$ under the case of $b=$ 0.63

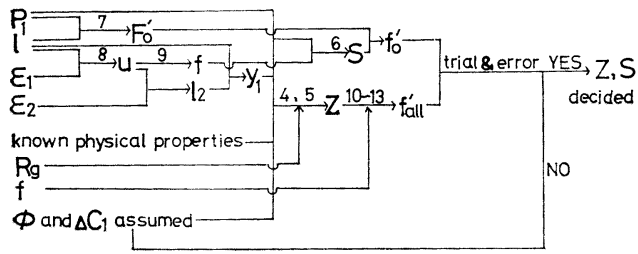

Fig. 2 Design procedure of a cyrindrical shaped crystallizer

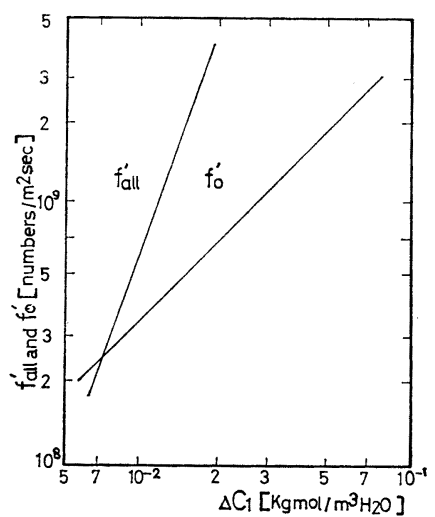

Fig. 3 Correlation between $f_{a l l^{\prime}}$ and $f_{0}{ }^{\prime}$ with $\Delta C_{1}$

線図化され，その線図は系あるいは粒径の絶対値にかか わらず使用できる．Fig. 1 には， $b=0.63$ の場合につい て (C.F.C.) $)_{n}$ を線図化して示してある.

2 次核発生速度を考慮した設計法は次の点で前報到ま でと異なる．まず入口溶液過飽和度 $\Delta C_{1}$, 無次元過飽和 度 $\phi$ を仮設定することによって Eqs. (4), (5) より仮設 定值に対応した装置を設計し，次に高さ方向の過飽和度 および粒径の分布を算出し，それより Eq. (1) にて微小 層高内の 2 次核発生速度を求め，それを装置全体に積分 することによって装置内に打ける2 次核発生速度の合計 を求める。 この算出 2 次核発生速度は，生産速度 $P_{1}$ 打 よび製品粒径 $l_{1}$ から決定される単位時間に必要な結晶 数に等しくなければならず,この条件を満足するように $\Delta C_{1}, \phi$ を決定する．以下，粒径が $l_{1}$ の結晶を生産速度 $P_{1}$ で得る場合について述べる. な敃設計手順を図式化

* Chem. Eng. Japan Vol. 37, No. 4, (1973) には, 粒径は装置 内で完全分級ではないか，高さ位置のモード径に着目すると，モ 一ド径に従った完全分級の分布が高さ方向にあるとして装置内の 特性を検討することの可能なことが示されている.
すると Fig. 2 のようになる. 条件のような製品結晶め 得るために単位時間に必要な結晶数 $F_{0}{ }^{\prime}$ は数収支式 Eq. (7) より得られる.

$$
F_{0}{ }^{\prime}=P_{1} / \rho_{\mathrm{c}} k_{v} l_{1}{ }^{3}
$$

運転条件として塔底部および塔頂部の空間率をそれぞれ $\varepsilon_{1}, \varepsilon_{2}$ と設定するとき, 空塔速度はアレンの領域で, 前 報同同様, 諏訪らの式を用いることによって Eq. (8) と なる.

$$
u=\varepsilon_{1}^{3} I l_{1} / K^{3}
$$

溶媒基準の溶液空塔速度 $f$ は Eq. (9) となる.

$$
f=C^{\prime} u
$$

また塔頂部粒径 $l_{2}$ は Eq. (8) で $\varepsilon_{1}$ のかわり $\varepsilon_{2}$ にを用い ることによって求まるので, 塔高 $Z$ および装置断面積 $S$ 海次元過飽和度 $\phi$ と入口溶液過飽和度 $J C_{1}$ が決ま った場合には，旮れぞれ Eqs. (4)〜 (6) で求まる。装置 内に拈ける高さ方向の粒径分布は, 完全分級を仮定すれ ば*, Eqs. (4) および (5) から $Z \sim y$ の関係で与えられ る. したがって前に述べたよらに, 単位断面積あたり装 置全体で単位時間に発生する核の数 $f_{\text {all }}{ }^{\prime}$ は Eq. (1)より Eq. (10) となる.

$$
\left.f_{\text {all }}{ }^{\prime}=\int_{0}^{z} f^{\prime} a d Z=\int_{0}^{z} a \alpha(R e)^{\beta}(\lrcorner C\right) r d Z
$$

装置単位容積あたりの結晶表面積 $a$ ，レイノルズ数 $R e$ および $\Delta C$ は Eqs. (11) (14) の上うに無次元粒径 $y$ に て表されるので，設定された $J C_{1} ， \dot{\phi}$ 汇基づいて設計さ れた装置内の核発生速度は算出できる。

$$
\begin{gathered}
\operatorname{Re}=u l / \nu \varepsilon=(\varepsilon / K)^{3} I_{2}{ }^{2} y^{2} / \nu \varepsilon \\
a=n k_{a} l^{2}=k_{a}(1-\varepsilon) / k_{v} l_{2} y \\
\Delta C=\left(\Delta C_{1} / \phi\right)\left\{1+(\phi-1)\left(y^{3}-1\right) /\left(y_{1}{ }^{3}-1\right)\right\} \\
\varepsilon=\varepsilon_{2} y^{-1 / 3}
\end{gathered}
$$

ここで算出された $f_{\text {all }}{ }^{\prime}$ と Eqs. (6) および (7) より算出 された $f_{0}{ }^{\prime}\left(=F_{0}{ }^{\prime} / S\right)$ とが等しいときのみ所望の粒径の結 晶および生産速度が得られることになる。したがって仮 設定された $\Delta C_{1}$ はこの関係を満足せね齐ばならず，この ような $\Delta C_{1}$ は次の手順で決定される。すすなわち，Eqs． (6) および (10) より $f_{0}{ }^{\prime}$ と $f_{\text {all }}{ }^{\prime}$ は入口溶液過飽和度 $\lrcorner C_{1}$ に対してそれぞれ Eqs. (15) および (16) となる.

$$
\begin{aligned}
f_{a l l}{ }^{\prime} & \propto \Delta C_{1} \gamma^{-n+1} \\
f_{0}{ }^{\prime} & \propto \Delta C_{1}
\end{aligned}
$$

この関係より，すでに設定された $\Delta C_{1}$ に対して $f_{0}^{\prime}$ 之 $f_{\text {all }}{ }^{\prime}$ を両対数点綴すると Fig. 3 のよう汇直線となり, それらの交点が条件の結晶を得るための $\Delta C_{1}{ }^{*}$ となる. この $\Delta C_{1}$ *を用いて再び $Z$ および $S$ を求めれば， それ が所望の結晶粒径 $l_{1}$ 㧍よび生産速度 $P_{1}$ を得るための装 置となる.

\section{2 -2 円錐分級層型晶装置の設計法}

円錐分級層型晶析装置の設計式は円筒型と同様汇晶析 


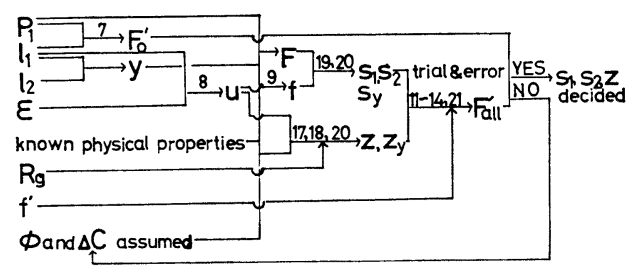

Fig. 4 Design procedure of a cone shaped crystallizer

操作特性因子 (C.F.C.) $)_{n, \varepsilon=\mathrm{const}}$ を用いて Eqs. (17) (19) となる.

$$
\begin{gathered}
\left.Z=\begin{array}{c}
3 \rho_{c} k_{v}{ }^{2} F_{0} I(\varepsilon / K)^{3} l_{2}{ }^{5-b} C^{\prime} \\
F k_{a}(1-\varepsilon) K_{g} \Delta C_{1}{ }^{n}
\end{array} \text { (C.F.C. }\right)_{n . \varepsilon=\operatorname{coost}} \text { (17) } \\
\text { (C.F.C. })_{n . \varepsilon=\mathrm{const}}=\int_{1}^{y_{1}}\left\{1+(\phi-1)\left(y^{3}-1\right) /\left(y_{1}{ }^{3}-1\right)\right\}^{n}
\end{gathered}
$$

$$
S=\left(P_{1}-P_{2}\right) / M C^{\prime} \Delta C_{1}(1-1 / \phi) I(\varepsilon / K)^{3} l_{2} y
$$

しかし円錐型の場合は, 装置高さの変化にともなって装 置断面積が变化するので, 任意の無次元粒径 $y$ に対応す る装置高さ $Z_{y}$ と装置断面積 $S_{y}$ の関係を求めて装置形 状を決定する必要がある. 前報) と同様に, $y$ に対応し た $Z_{y}$ は Eqs. (17) および (18) で $y_{1}$ のかわりに $y$ を, また $\phi$ のかわりに Eq. (20) から算出される $\phi_{y}$ を用いる と, $y$ に対応した $Z$ 同様に得られる.

$$
\phi_{y}=\left\{(\phi-1) /\left(y_{1}^{3}-1\right)\right\}\left(y^{3}-1\right)+1
$$

同様にして $y$ に対応した $S_{y}$ も求まるので， $y$ をパラメ 一タとして $Z_{y}$ および $D_{y}\left(=2 \sqrt{ }\left(S_{y} / \pi\right)\right)$ を点経すれば, 装 置が設計できる。これらを用いた設計は，円筒型同様， Fig. 4 で示される手順でなされる. 円錐型において断面 積は高さ方向に異なるので, 結晶数の算出には Eq. (21) のように $S$ を乗じた全断面積あたりのものを用いねばな らない.

$$
F_{a l l}{ }^{\prime}=\int_{0}^{z} a \alpha(R e)^{\beta}(\Delta C)^{\gamma} S d Z
$$

\section{$1 \cdot 3 \Delta L$ 法則を仮定した場合の設計法}

晶析装置内で $\Delta L$ 法則を仮定すると Eq. (2) の結晶成 長速度は過飽和度の関数 $(b=0)$ として表すことができ る.したがって設計式は簡単化され，Eqs. (4), (5), (7) および (18)で $b=0$ と拈いたものとなり, 晶析操作特性 因子 (C.F.C.) $)_{n . b=0},(\text { C.F.C. })_{n . \varepsilon=\mathrm{const} b=0}$ は，それぞれ Figs. 5 扰よび 6 となる. 成長速度が $\Delta L$ 法則に従 らと いうことは, 成長速度に粒径の影響を考えないというこ とであり，Branson モデルに基づく成長速度を平均成長 速度で表した場合に払張して考えることができる．この 場合, Branson モデルの成長速度式は平均粒径 $l_{a v}$ を用

\footnotetext{
* 平均粒径の定義には重みとして成長速度をとるもの，その他が考 えられるが, 粓径分布のある系から成長速度を実測する場合, 個 数基準の平均粒径を用いるのが扱いやすく，この定義による平均 粒径を用いた場合の適用可否の検討は工学上重要であるので, Eq. (23) による定義を用いる。
}

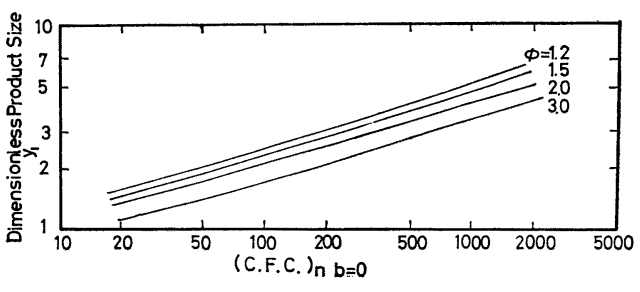

Fig. 5 Correlation between (C.F.C.) $n . b=0$ and dimensionless product size $y_{1}$ under the case of $b=0$

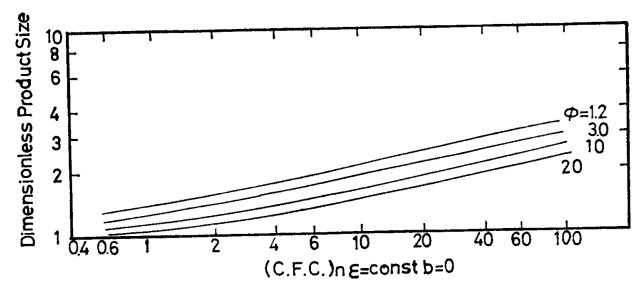

Fig. 6 Correlation between (C.F.C.) $)_{n, \varepsilon=\operatorname{const} b=0}$ and dimensionless product size $y_{1}$ under the case of $b=0$

Table 1 Calculations of the dimensions of cyrindrical-shaped classifying crystallizers production rate $=30$ ton/ day product size $=0.9 \mathrm{~mm}$

\begin{tabular}{lll} 
& \multicolumn{1}{c}{$\begin{array}{c}\text { The case used } \\
\text { Branson's model }\end{array}$} & \multicolumn{1}{c}{$\begin{array}{l}\text { The case used } \\
\text { Delta } L \text { law }\end{array}$} \\
\hline$R_{g}\left[\mathrm{~kg} / \mathrm{m}^{2}\right.$-sec $]$ & $2.09 l 0.63 \Delta C^{1.62}$ & $3.09 \times 10^{-2} \Delta C^{1.62}$ \\
$\begin{array}{c}f_{\text {all }}[\mathrm{number} / \\
\left.\mathrm{m}^{2} \text {-hr }\right]\end{array}$ & $3.80 \times 10^{8}$ & $3.65 \times 10^{8}$ \\
$Z[\mathrm{~m}]$ & 2.50 & 2.60 \\
$S\left[\mathrm{~m}^{2}\right]$ & 5.28 & 5.55 \\
\hline
\end{tabular}

いることによって Eq. (22) で表される.

$$
R_{g}=K_{g}\left(l_{a v}\right)^{b}(\Delta C)^{n}
$$

ここで, 平均粒径 $l_{a v}$ は個数基準で, 塔頂から塔底まで の間に存在する全結晶数 $N$ と $d l$ 幅の粒径 $l_{i}$ の結晶個 数 $n_{i}$ によって Eq. (23) にて定義されるものである*.

$$
l_{a v}=\int n_{i} l_{\imath} d l / N
$$

Branson モデルで結晶成長速度を定量化する場合，狭い 粒径範囲で結晶を成長させて, 粒径の影響を厳密に実測 する必要があるが，粒径の影響を平均化した $\Delta L$ 法則を 適用できれば，ある程度幅のある粒径を持つ結晶群を用 いて成長実験を行い，そのデータに基ついて装置設計が 可能になる. そこで Mullin らのカリ明礬系の結晶成長 速度式 Eq. (24)を用いて

$$
R_{g}=2.90 l^{0.63} \Delta C^{1.62}
$$

Eqs. (4), (5) 执よび (6) から得た設計值と，Eq. (24)の $l$ に対して Eq. (23) にて定義される $l_{a v}$ を用いて得られ る平均結晶成長速度を用い， $b=0$ として得られた設計 値とを比較すると Table 1 のごとくなった. この設計 計算は, $0.9 \mathrm{~mm}$ の正八面体カリ明攀を 1 日 30 ton 生産 する円筒分級層型晶析装置を設計する場合で, 両者の差 


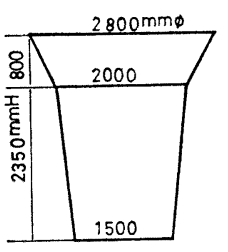

Fig. 7 Dimension of the cone shaped crystallizer

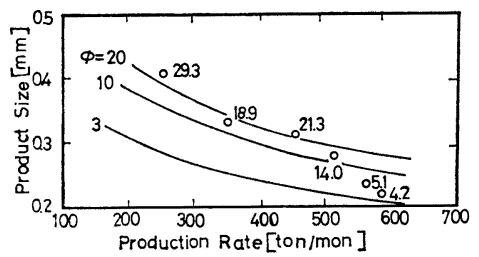

Fig. 8 Correlation between product size and production rate

Table 2 Test's data of the cone- shaped crystallizer

\begin{tabular}{ccc}
$\begin{array}{c}l_{1} \\
{[\mathrm{~mm}]}\end{array}$ & $\begin{array}{c}\phi \\
{[-]}\end{array}$ & $\begin{array}{c}P_{1} \\
\text { [ton/mon] }\end{array}$ \\
\hline 2.2 & 4.2 & 600 \\
2.4 & 5.1 & 580 \\
2.8 & 14.0 & 524 \\
3.2 & 21.3 & 454 \\
3.4 & 18.9 & 367 \\
4.1 & 29.3 & 260
\end{tabular}

異は装置形状劣よび入口溶液過飽和度について $5 \%$ 以内 で，工業装置の設計に $\Delta L$ 法則 $(b=0)$ を適用できる可 能性は大と考えられる.

\section{2. 晶析装置における操作条件と製品結晶との関係}

すでに設計された円錐分級層型晶析装置の生産速度と 製品粒径との関倸は，以下の手順にて推算できる.

装置はすてに設計されているので， $Z, S_{1}, S_{2}$ は既知で ある. 推算により， $\phi$ をパラメータとして， $P_{1}$ に対応 する製品粒径 $l_{1}$ を算出する.

1）設定された $P_{1}, \phi$ に対して, 溶液循環量 $F$ および 操作可能な範囲内で, 一定の塔内空間率 $\varepsilon$ を仮定する.

2) 製品粒径 $l_{1}$ は， $F, \varepsilon, S_{1}$ および $S_{2}$ がそれぞれ既 知であるので, Eq. (8) より算出される.

3)この時に単位時間あたり必要とする結晶数 $F_{0}{ }^{\prime}$ は $P$ と算出 $l_{1}$ より物質収支式 Eq. (7) にて, また入口溶液 過飽和度 $J C_{1}$ は装置内溶液の物質収支式 Eq. (25) より それぞれ求められる。

$$
\lrcorner C_{1}=P\left(1-1 / y_{1}^{3}\right) / M F(1-1 / \phi)
$$

4) 無次元粒径心対する $R e, \Delta C, Z$ および $S$ の值を Eqs. (11), (13)，(17) 抢よび (19) から求め, それを用い ると Eq. (21) より核発生速度 $F_{a l l}{ }^{1}$ が求まる. この $F_{a l l}{ }^{1}$ は $F$ に対して両対数点経すると, Fig. 2 と同様に勾配 $2 \beta-\gamma-1$ の直線となる. 一方, 3) で求めた $F_{0}{ }^{\prime}$ は $F$ に 対して一定となるので, 同一グラフに点綴することによ って, $F_{0}{ }^{\prime}=F_{a l l}{ }^{\prime}$ を満足する $F$ を求めることができ，そ
れに対応した粒径 $l_{1}$ を決定できる.

Fig. 7 はカリ明䄷晶析のための円錐分級層型晶析装置 である.この装置のテストデータは Table 2 に示す. 一 方前述の手法にて, この装㯰で得られる結晶粒径と生産 速度との関係を求めて点経すると Fig. 8 となった。この 算出では，2次核発生速度は前報で得られた Eq. (26) を，また結晶成長速度は，著者らが測定した線成長速度 Eq. (27) を用いた.これは，工業装置から得られた結晶 粒径の㬰測值と対比しらるように，顕微鏡撮影にて粒径 の変化から求めた平均粒径に基つく成長速度である.

$$
\begin{gathered}
f^{\prime}=1.0 \times 10^{5}(\operatorname{Re})^{2.5}(\Delta C)^{3.3} \\
r=5.0 \times 10^{-5}(\Delta C)^{5 / 3}
\end{gathered}
$$

また Table 2 のテストデータも同時に点綴した. 図より 明らかなよらに，前報のデータに基づく推算値はテスト データとよく一致した.

\section{結言}

2 次核発生速度がレイノルズ数と過飽和度で相関され る場合について，2次核発生速度と結晶成長速度に基づ く新しい分級層型晶析装置の設計法を提出した。またす でに設計された装置における操作条件と製品結晶との関 係を推算する方法についても提案した. それらの設計法 および推算法に基づて工業装置の検討を行い，次のよ らな結論を得た。

1）カリ明䄷系で，われわれが測定した 2 次核発生速 度と結晶成長速度に基ついて推算した結晶生産量と製品 粒径との関係は, 工業操作データと比較的よく一致し た。このことから，新しい設計法を用いれば，一万倍程 度のスケールアップが可能であると考える.

2) 工業装置, 操作の設計に関しては, 近似的に $\Delta L$ 法則を用いることができる.

\section{Nomenclature}

$a=$ total crystal surface area per unit volume of crystallizer $\left[\mathrm{m}^{2} / \mathrm{m}^{3}\right]$

$b=$ order used in Branson model Eq. (2) [-]

(C.F.D.) $=$ characteristic factor of diffusion step

(C.F.S.R.) $=$ characteristic factor of surface reaction

(C.F.C. $)_{n}=$ characteristic factor of crystallization with cyrindrical shaped crystallizer [-]

(C.F.C. $)_{n, \varepsilon=\mathrm{const}}=$ characteristic factor of crystallization with cone shaped crystallizer in which $\varepsilon$ is kept constant [-]

(C.F.C. $)_{n . b=0}=$ characteristic factor of crystallization with cyrindrical shaped crystallizer in which delta $L$ low is assumed

(C.F.C. $)_{n . \varepsilon=\text { const. } b=0}=$ characteristic factor of crystallization with cone shaped 
crystallizer in which $\varepsilon$ is kept constant and delta $L$ low is assumed

$\Delta C=$ solution supersaturation

[kg-mol $/ \mathrm{m}^{3}$ (solvent)]

$\Delta C_{1}=$ inlet solution supersaturation

[kg-mol $/ \mathrm{m}^{3}$ (solvent)]

$\Delta C_{2}=$ outlet solution supersaturation

[kg-mol $/ \mathrm{m}^{3}$ (solvent)]

$C^{*} \quad=$ working solution supersaturation which is finally decided in the design procedure [ $\mathrm{kg}-\mathrm{mol} / \mathrm{m}^{3}$ (solvent)]

$C^{\prime}=$ solution concentration [ $\mathrm{m}^{3}$ (solvent) $/ \mathrm{m}^{3}$ (solution)]

$D_{y}=$ diameter of crystallizer at the height $Z_{y}$

$F \quad$ circulation rate based on solvent $\left[\mathrm{m}^{3}\right.$ (solvent)/sec]

$F_{0}{ }^{\prime}=$ total number of product crystal per unit time in a crystallizer [number/sec]

$F_{a l l}{ }^{\prime}=$ total secondary nucleation rate

[number/sec]

$f \quad=$ superficial velocity of solvent $[\mathrm{m} / \mathrm{sec}]$

$f^{\prime}=$ secondary nucleation rate per unit crystal surface area [number $/ \mathrm{m}^{2}$-sec]

$f_{0}^{\prime}=$ number of product crystal per unit time and unit cross sectional area of crystallizer [number $/ \mathrm{m}^{2}$-sec]

$f_{a l l}{ }^{\prime}=$ total secondary nucleation rate per unit time and unit cross sectional area of crystallizer [number $\left./ \mathrm{m}^{2}-\mathrm{sec}\right]$

$I=$ terminal verocity constant

$K=$ constant used in Eq. (8)

$K_{g}=$ crystal growth rate constant under the case used Branson model $\left[\mathrm{kg} / \mathrm{m}^{2} \sec (\Delta \mathrm{C})^{n} l^{b}\right]$

$k_{a}=$ surface shape factor

$k_{v}=$ volume shape factor

$l=$ crystal size

$l_{1}=$ crystal size at the bottom of crystallizer or product size

$l_{2} \quad=$ crystal size at the top of crystallizer [m]

$M \quad=$ molcular weight of crystal-material

$N=$ total number of crystal which exists [kg/kg-mol] in crystallizer $n=$ order of crystal growth rate

$n_{i}=$ number of crystal whose crystal size is $l_{i}$

$P_{1} \quad=$ production rate

$P_{2} \quad=$ assumed feed rate of crystal

$R_{\boldsymbol{g}}=$ crystal growth rate

$r \quad=$ liniar growth rate

$\operatorname{Re}=$ Reynolds number

$S=$ cross sectional area of crystallizer $\left[\mathrm{m}^{2}\right]$

$S_{y}=$ cross sectional area at the height $Z_{y}\left[\mathrm{~m}^{2}\right]$

$u=$ superficial solution velocity [m/sec]

$v \quad=$ volume of individual crystal in a

crystallizer $\quad\left[\mathrm{m}^{3}\right]$

$[\mathrm{kg} / \mathrm{sec}]$

$[\mathrm{kg} / \mathrm{sec}]$

$\left[\mathrm{kg} / \mathrm{m}^{2}-\mathrm{sec}\right]$

$[\mathrm{m} / \mathrm{sec}]$

$y_{1}=$ dimensionless crystal size of product $[-]$

$Z=$ height of crystallizer [m]

$Z_{y} \quad=$ height from the top of crystallizer at which crystal size $y$ is fluidized [m]

$\alpha=$ secondary nucleation rate constant

$\beta \gamma=$ order of secondary nucleation rate

$\phi=$ diemnsionless supersaturation [-]

$\phi_{y}=$ dimensionless supersaturation at the height $Z_{y}$

$\varepsilon \quad=$ void fraction

$\varepsilon_{1}=$ void fraction at the bottom of

crystallizer [-]

$\varepsilon_{2}=$ void fraction at the top of crystallizer [-]

$\rho_{c}=$ crystal density $\quad\left[\mathrm{kg} / \mathrm{m}^{3}\right]$

$v=$ kinematic viscocity $\quad\left[\mathrm{m}^{2} / \mathrm{sec}\right]$

\section{Literature cited}

1) Aoyama, Y. and K. Toyokura: Kagaku Kōgaku, 37, 416 (1973)

2) Branson, S. H.: Brit. Chem. Eng., 5, 838 (1960)

3) C. E. P. Symposium Series, 121, 68, 57 (1972)

4) Hirota, S., K. Fukui and M. Nakajima: Kagaku Kogaku Ronbunshu, 5, 500 (1975)

5) Mullin, J. W. and J. Garside: Trans. Instn. Chem. Engrs., 45, T291 (1967)

6) Shirotsuka, T., K. Toyokura and Y. Sekiya: Kagaku Kōgaku, 29, 668 (1965)

7) Toyokura, K. and K. Yamazoe: Kagaku Kogaku Ronbunshu, 1, 262 (1975)

(1976 年 4 月 9 日受理; 化学工学協会第 8 回秋季大会 (東京, 1974 年 10 月), 同第 9 回秋季大会 (九州, 1975 年 10 月) および同第 40 年会 (名古屋, 1975 年 4 月) にて発表)

\title{
Design Method of Classifying Crystallizers based on Secondary Nucleation Rate
}

\author{
Ken Toyokura, Natsunosuke Yago and Katsumi Yamazoe \\ Dept. Applied Chem., Waseda Univ., 160 \\ Yoshio Aoyama \\ Daidoh Kakoki Co., Ltd., Osaka, 554
}

A new design method of classifying crystallizers (cone and cyrindrical shaped types) is proposed on the basis of not only crystal growth rate, but secondary nucleation rate for potassium alum reported in the previous paper. Further, the method for estimation of the correlation between product size and production rate under the operational conditions of a fixed industrial crystallizer is also studied. The estimated values from the laboratory data of the crystallization of potassium alum are compared with data obtained from an industrial crystallizer that is actually operated. They agree fairly well, and as a result, it is suggested that about a hundred thousand times scale-up from data of a laboratory scale fluidized crystallizer to an industrial one may be possible by the use of the proposed method. 